\title{
AEROTHERMAL TEST OF THERMAL PROTECTION SYSTEMS FOR X-33 REUSABLE LAUNCH VEHICLE
}

\author{
*James Wayne Sawyer, *Jefferson Hodge, **Brad Moore, **Kevin Snyder \\ *NASA Langley Research Center, Hampton, VA, USA \\ **B.F. Goodrich Aerospace, Chula Vista, CA, USA
}

\begin{abstract}
An array of metallic Thermal Protection System (TPS) panels developed for the windward surface of the X-33 vehicle was tested in the 8-Foot High Temperature Tunnel at the NASA Langley Research Center. These tests were the first aerothermal tests of an X-33 TPS array and the test results will be used to validate the TPS for the X-33 flight program. Specifically, the tests evaluated the structural and thermal performance of the TPS, the effectiveness of the high temperature seals between adjacent panels and the durability of the TPS under realistic aerothermal flight conditions. The effect of varying panel-to-panel step heights, intentional damage to the seals between adjacent panels, and the use of secondary seals were also investigated during the test program. The metallic TPS developed for the windward surface of the X-33, the blanket TPS developed to protect the leeward surfaces of the X-33, and the test program in the 8-Foot High Temperature Tunnel are presented and discussed.
\end{abstract}

\section{INTRODUCTION}

NASA is committed to work with the aerospace industry to develop a Reusable Launch Vehicle (RLV) that will greatly reduce the cost of launching a payload into space. A single-stage-to-orbit RLV was selected as having the most potential for reducing launch costs (Anon, 1994 and Becky, 1994). NASA and an industry team led by Lockheed Martin have selected a lifting body configuration (see figure 1) referred to as the VentureStar ${ }^{\mathrm{TM}}$ for further development (Baumgartner, 1997, 1998). The VentureStar ${ }^{\mathrm{TM}}$ is projected to have refractory composite leading edges, control surfaces and fairings in the highest heating areas and metallic thermal protection system (TPS) over the remainder of the vehicle. Metallic TPS were selected because of their good durability and low maintenance and operations costs.

A half scale vehicle referred to as the X-33 (Cook, 1996) is being designed and fabricated, and will be flown to validate technologies for use on the VentureStar ${ }^{\mathrm{TM}}$. The high heating areas of the $\mathrm{X}-33$ will be fabricated using refractory composite hot structure and metallic TPS similar to that planned for the VentureStar ${ }^{\mathrm{TM}}$ (see figure 2). The TPS on the windward surface of the X-33 will consist of Inconel 617 or PM-1000 (the PM-1000 material will be used in the slightly higher heating areas near the nose cap) superalloy honeycomb sandwich surface panels and fibrous insulation enclosed in attached foil bags. To reduce cost, the leeward surface of the X-33 will be covered by insulation blankets similar to those used on the Space Shuttle. The blankets consist of fibrous insulation enclosed in a quartz cloth and directly bonded to a graphite composite aeroshell.

A metallic TPS has been developed for the windward surface of the X-33 vehicle and an array of these TPS panels has been tested in the 8-Foot High Temperature Tunnel at NASA Langley Research Center. The 8Foot High Temperature Tunnel provides a combination of aerodynamic heating and pressure loading on the TPS array that is representative of critical flight conditions on the X-33. These tests were the first aerothermal tests of a metallic X-33 TPS array and will be used to validate the TPS for the X-33 flight program. Specifically, the tests evaluated the structural and thermal performance of the TPS, the effectiveness of the high temperature seals between adjacent panels and the durability of the TPS system under realistic aerothermal flight conditions. The effect of varying panel-to-panel step heights, damage to the seals between adjacent panels, and the use of secondary seals were also investigated during the test program. 


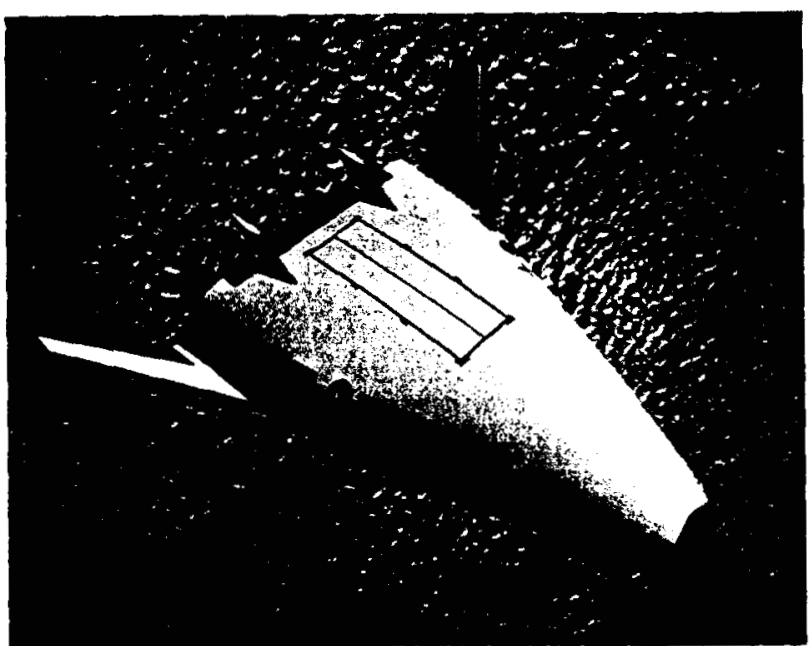

FIGURE 1. VentureStar $T^{\mathrm{M}}$ Vehicle Configuration.

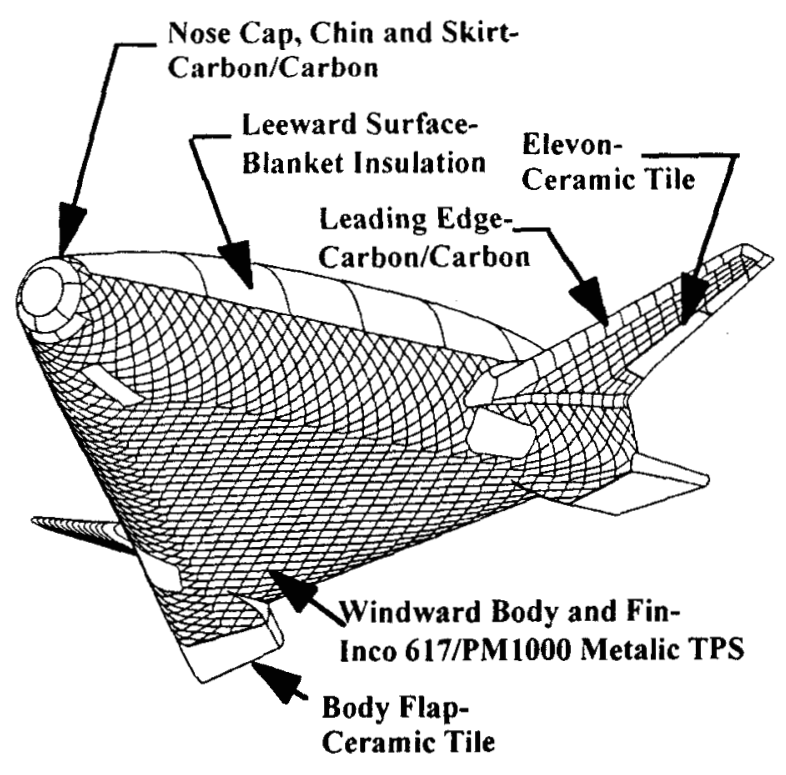

FIGURE 2. Thermal Protection System proposed for the X-33 Vehicle.

The blanket insulation for the leeward surface of the X-33 vehicle was also tested in the 8-Foot High Temperature Tunnel at NASA Langley Research Center. These tests evaluated the structural and thermal performance and durability of the blanket system bonded to a graphite epoxy panel and subjected to multiple cycles of expected X-33 flight loads.

The metallic TPS developed for the windward surface of the X-33, the blanket system proposed for the leeward surface of the $\mathrm{X}-33$ and the test program in the 8-Foot High Temperature Tunnel are discussed in this paper. Limited test results are also presented and discussed.

\section{APPARATUS AND TESTS}

The test program consisted of subjecting flat test panels representative of TPS being fabricated for the windward and leeward surfaces of the X-33 vehicle to realistic flight aerothermal environments. The TPS test panels were mounted in a panel holder for aerothermal tests in the Mach 7, 8-Foot High Temperature Tunnel at NASA Langley Research Center. Tunnel combustor pressure and the angle of attack of the panel holder with respect to the tunnel flow was varied to simulate combined aerodynamic pressure, shear loads, and aerodynamic heating thermal loads over the test panel that are expected during the X-33 flight program. The TPS test panel was preheated with radiant heaters to generate temperature distributions in the test model representative of $\mathrm{X}-33$ reentry conditions before insertion into the flow.

\section{Windward Surface TPS}

\section{TPS Description}

The TPS being developed for the windward surface of the X-33 consists of diamond shaped metallic panels approximately $46 \mathrm{~cm}$ along a side edge (Blosser, 1997, 1998). The TPS panels consist of a metallic honeycomb sandwich heat shield outer panel with foil-encapsulated fibrous insulation attached to the inner side of the heat shield panel. Each diamond-shaped panel is mechanically attached to a metallic stand-off attachment clip at each corner which is, in turn, attached to a composite support structure (see figure 3 ). The foil outer face sheets of the honeycomb sandwich panels overlap the surface of the downstream TPS panels to form sliding metal-to-metal seals between panels as shown in figure 4 . Foil strips attached to the inner face sheets of each panel and bent at $45^{\circ}$ as shown form secondary seals between panels. The overlapping primary seals and the secondary seals must prevent hot gas flow into the gaps between panels and support a pressure differential across the TPS panel. 
The metallic TPS wind tunne! test article consisted of an array of flat Inconel 617, X-33 TPS panels approximately $0.8 \mathrm{~m}$ by $1.4 \mathrm{~m}$ mounted in a test panel holder as shown in figure 5 . The array consisted of one full TPS panel and six panel segments to form the rectangular configuration shown in figure 6 . The TPS panels were orientated so that the short diagonals of the diamond shaped panels were aligned with the flow over the panel array. The panels were made of two $0.15-\mathrm{mm}$ Inconel 617 face sheets that are brazed to Inconel 617 honeycomb core $(4.7 \mathrm{~mm}$ square cells and $0.04 \mathrm{~mm}$ foil thickness). The surface of the TPS panels was painted with Pyromark $2500^{\mathrm{TM}}$ thermal paint to achieve a high uniform emissivity. Three centimeters of $0.056 \mathrm{~g} / \mathrm{cm}^{3}$ Q-fiber felt insulation were encapsulated on the backside of each honeycomb panel with a resistance welded $0.08 \mathrm{~mm}$ thick Inconel 617 pan. The TPS panels were mechanically attached to and supported by Rene' 41 standoff attachment clips located at each intersection of the TPS panels as shown in figure 5. The standoffs were mechanically attached to aluminum I-beams supported in a steel plenum chamber that surrounded the back side of the TPS panel array.



FIGURE 3. Metallic TPS configuration proposed for the X-33 and VertureStar ${ }^{\mathrm{TM}}$ vehicle.

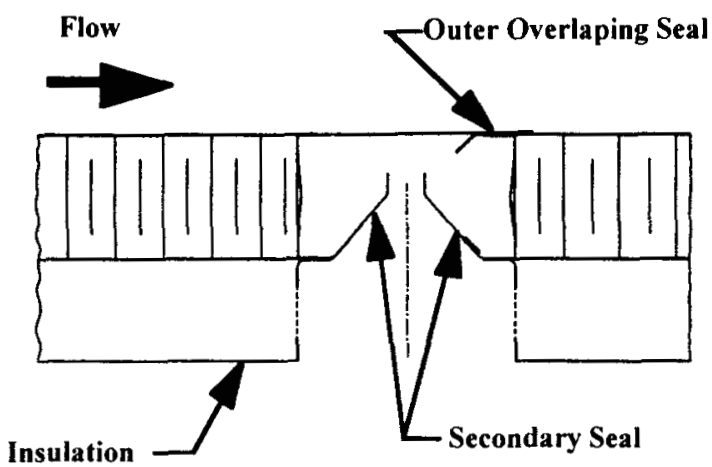

FIGURE 4. Seal configuration between metallic TPS panels. (View AA in figure 3.)

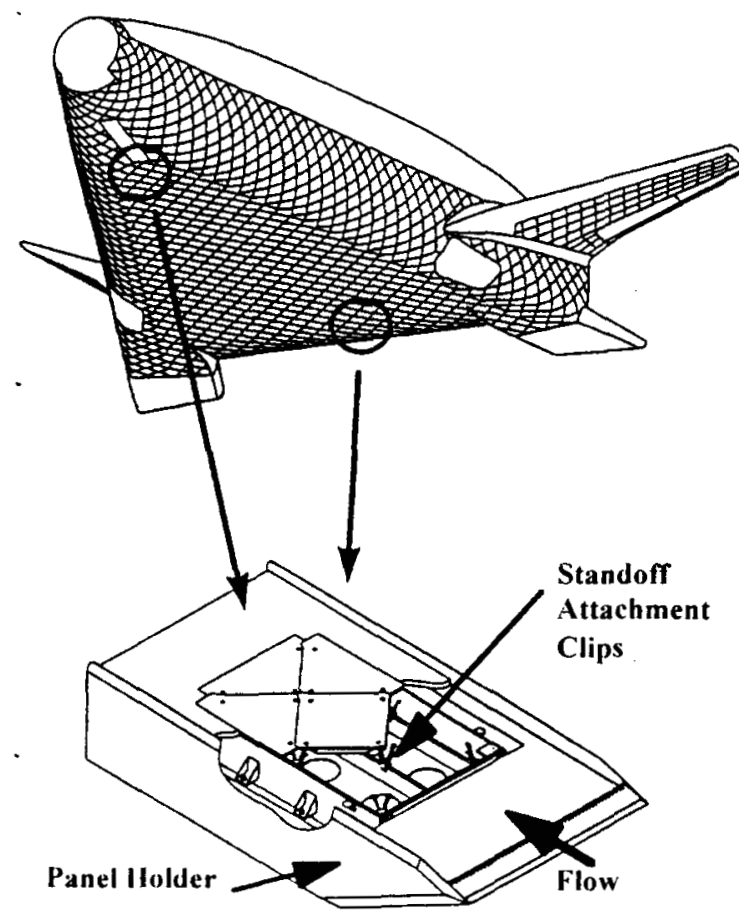

FIGURE 5. Typical vehicle locations for TPS test pancl array.

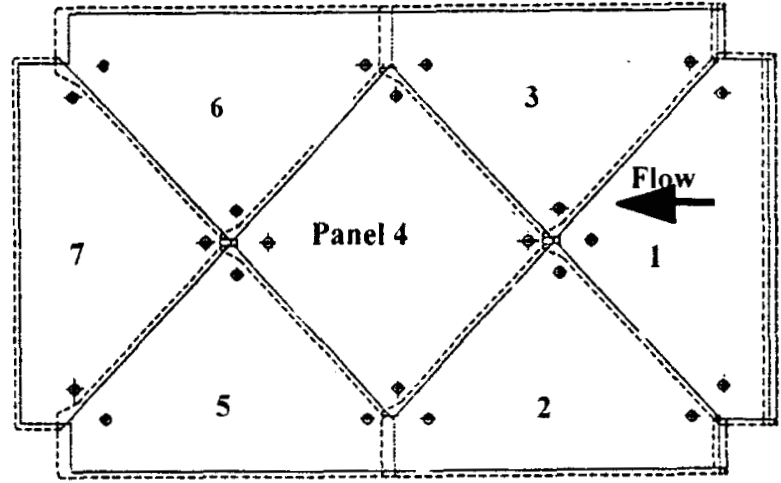

FIGURE 6. Metallic TPS panel array for 8 Foot High Temperature Tunnel tests (top view). 
The TPS panel array was mounted in the wind tunnel panel holder by attaching the plenum box to rails on the inside walls of the cavity in the panel holder (see figure 7). The attachment of the plenum chamber to the panel holder was shimmed so that the surface of the TPS panel was approximately flush with the glassrock surface of the panel holder on the side edges and the trailing edge. The $0.15 \mathrm{~mm}$ thick outer facesheet of the honeycomb sandwich TPS panel extended approximately $2.5 \mathrm{~cm}$ over the glass rock surface of the panel holder along the two sides and the trailing edge of the test article as shown in figure 8 . The leading edge of the test article was recessed approximately $0.6 \mathrm{~cm}$ below the glassrock panel holder surface to insure that thermal bowing of the TPS panel array did not result in a forward facing step to the flow. Also an L-shaped Inconel 617 foil bracket $0.25 \mathrm{~mm}$ thick was attached to the forward surface of the panel holder cavity and extended approximately $2.5 \mathrm{~cm}$ downstream over the leading edge of the TPS panel array as shown in figure 9 . Rope seals were used around the periphery of the TPS panel array to guard against hot gas flow between the TPS panels and the glass rock insulation on the panel holder. A photograph of the test article installed in the panel holder in the 8-Foot High Temperature Tunnel is shown in figure 10.

\section{Instrumentation}

The TPS test panel and the panel holder were instrumented with a flow meter, a microphone, an accelerometer, 2 calorimeters, 2 surface pressure taps, 57 strain gages, and 56 thermocouples. In addition, 2 pressure probes and 6 thermocouples were located in the plenum chamber below the test panels to provide a measure of the chamber conditions during the tests. Video cameras were used throughout the tests and a thermography system was used to record temperature variations over the surface of the TPS panels while in the flow stream. The instrumentation leads and the pressure taps were routed through the base of the plenum chamber and out through the panel holder sting. A RTV rubber seal was used to prevent flow into and out of the plenum chamber through the exit hole for the instrumentation.
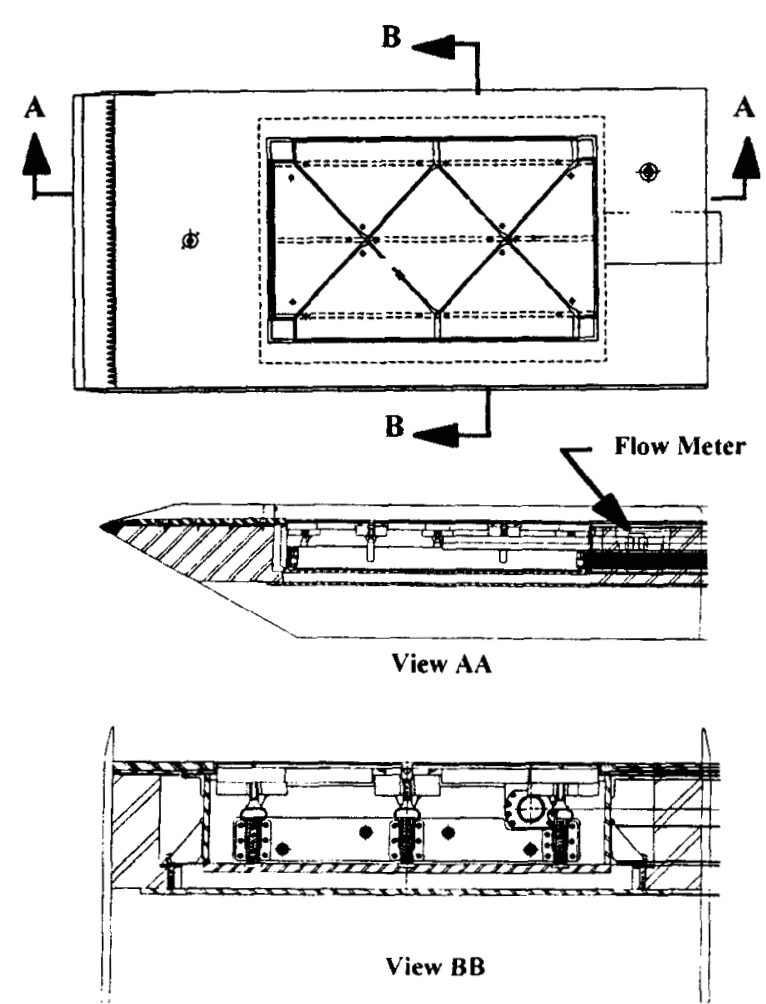

FIGURE 7. Mounting of TPS panel array in panel holder.

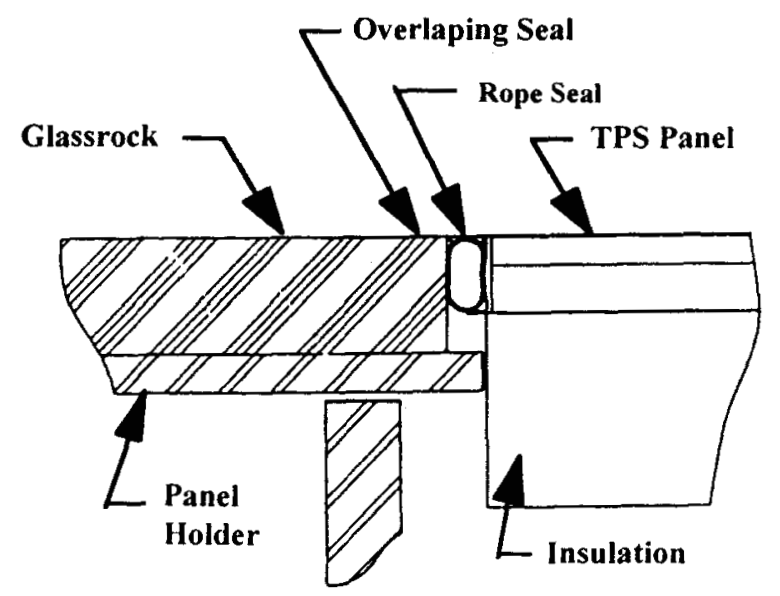

FIGURE 8. Side and trailing edge seals between TPS test panel array and panel holder. 


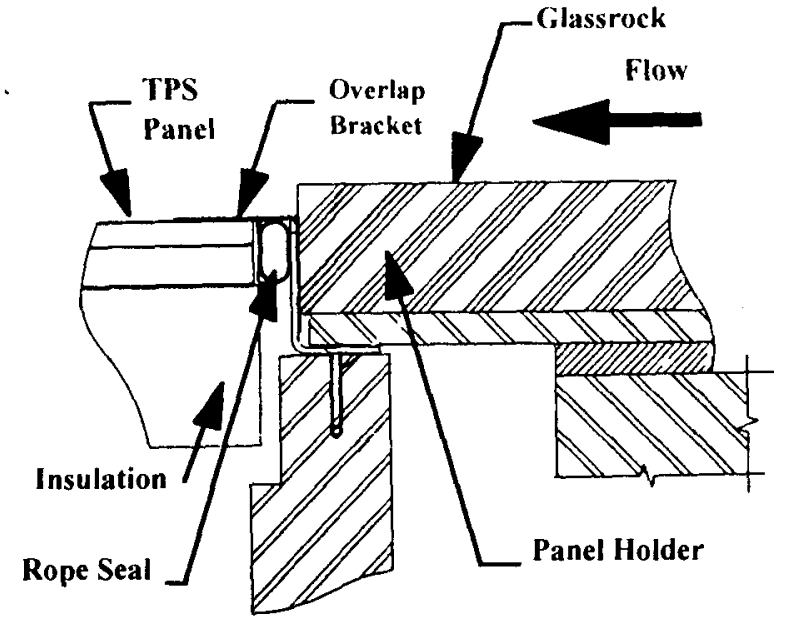

FIGURE 9. Leading edge seal between TPS panel array and panel holder.

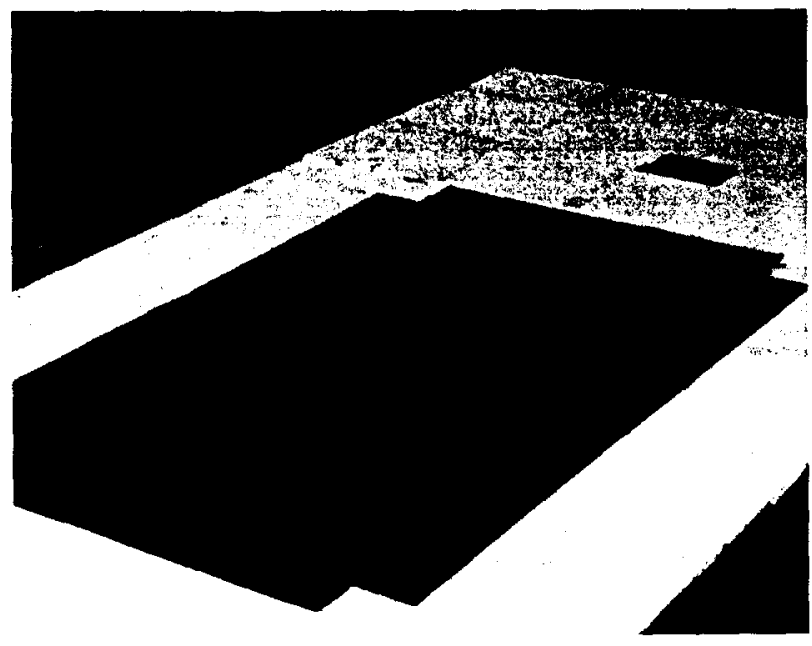

FIGURE 10. Photograph of TPS panel array and panel holder installed in wind tunnel.

The flow meter was located at the downstream end of the plenum chamber and was vented to the base of the test sled as shown in figure 7. The flow meter was attached to the plenum chamber by a flange fitting and a tube that extended approximately $69 \mathrm{~cm}$ inside the chamber. A $5.1 \mathrm{~cm}$ diameter flow meter and tube assembly was installed in the test setup but an alternate $2.5 \mathrm{~cm}$ diameter flow meter and tube assembly was available if the flow out of the plenum chamber was not sufficient to require the large flow meter. A thermocouple was mounted in the exit of the flow meter to measure the temperature of the air flowing out of the plenum chamber.

The microphone was flush mounted in the surface of the panel holder behind the TPS test panel array and to the right of center of the panel holder as shown in the layout in figure 11. The accelerometer was flush mounted in panel 6 . One of the calorimeters was flush mounted on the centerline of the panel holder approximately $25 \mathrm{~cm}$ upstream of the TPS panel array. The other calorimeter was located in the center of the interface between panels 3 and 4 and was mounted directly below the aerodynamic seals. The two static pressure taps were flush with the surface of the TPS panels and one was located in the center of panel 4 and the other one was located in panel 5.

Both low- (WK-type) and high-temperature (NZ-type) strain gages were installed on the test article. The high-temperature gages were located on the standoff attachment clips near the surface of the TPS panels and on the inner surface of the honeycomb sandwich outer panels. Low-temperature strain gages were used on the lower parts of the standoff attachment clips where they attach to the substructure. The strain gages were located on TPS panels 2, 4 and 5 and on the four standoffs supporting panel number 4, the center panel in the TPS test array. Panel 4 had strain gages installed near the center of the panel and at the side locations shown in figure 12. All the strain gages on the TPS panels were installed on the inner face sheets of the honeycomb sandwich panels. Panels 2 and 5, which were close-out panels with only two sides adjacent to other TPS panels, were also instrumented with strain gages on the sides adjacent to other TPS panels and the gages were oriented similar to those shown in figure 12 for panel 4 . High-temperature (NZ-type) strain gages were installed on the straight portions of the standoffs near the point where they attach to the TPS panels and lowtemperature (WK-type) strain gages were installed on the straight portions of the attachment clips near the point where they attach to the aluminum I-beams. The strain gages on the attachment clips were aligned with the legs of the clips. Both static and dynamic strain gages were installed on both the standoffs and the honeycomb sandwich panels. 


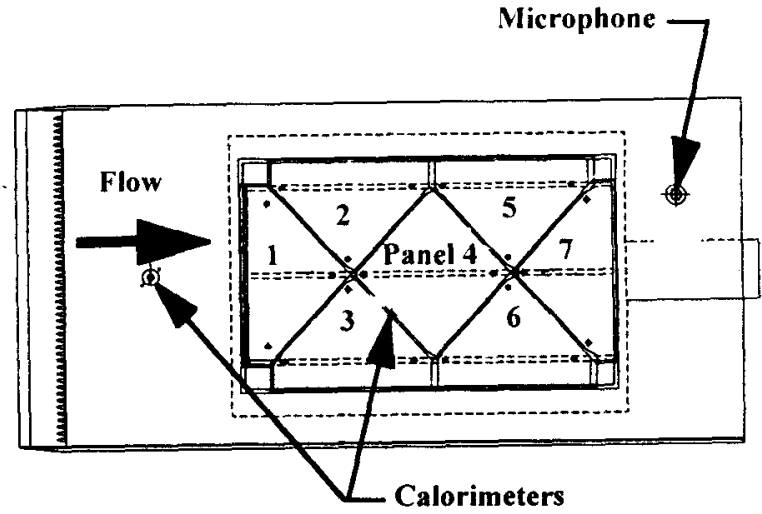

FIGURE 11. Layout for TPS test panel array in panel holder.

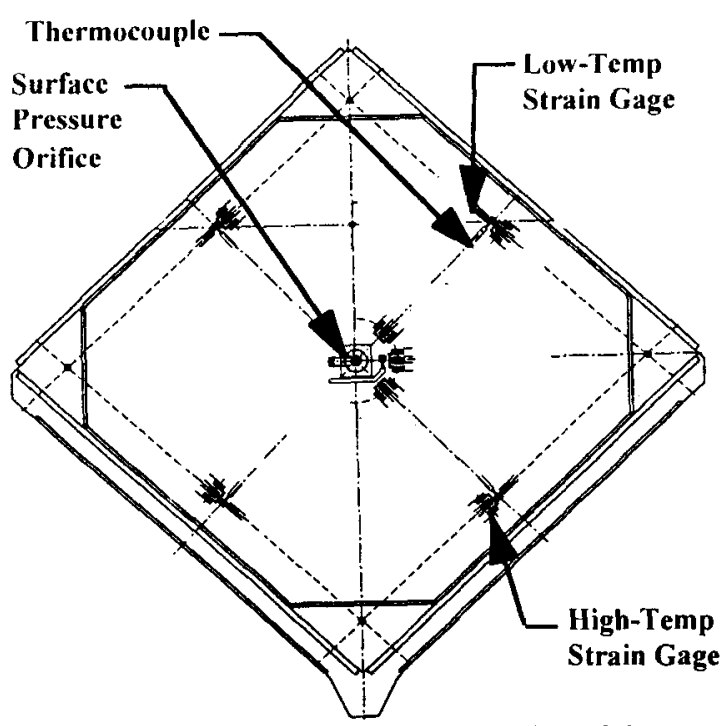

FIGURE 12. Instrumentation on the back side of the central panel (panel 4) in the TPS array.

Thermocouples were installed near each of the strain gages so that the strain gage data could be corrected for apparent strain variations due to temperature changes. Thermocouples were also installed on the inside of the inner and outer facesheets of the honeycomb sandwich panels, on the plenum chamber side of the foil package surrounding the fibrous insulation, on the attachment clips, on the primary and secondary seals between the panels, in the cavities between the panels, between the panels and the plenum chamber walls and in the cavity behind the TPS panel assembly. The thermocouples on the outer facesheets of the TPS panels were used to control the surface temperatures of the TPS array during the preheat thermal cycles and to monitor the surface temperatures during the aerothermal tests. The thermocouples on the inner facesheets of the honeycomb sandwich panels and on the plenum chamber side of the insulation packages were used to evaluate the thermal effectiveness of the TPS panels. The thermocouples on the seals and in the plenum chamber cavity were used to evaluate the effectiveness of the aerodynamic seals in preventing hot gas flow into the plenum chamber.

\section{Leeward Surface TPS}

\section{TPS Description}

The TPS used for the leeward surface of the X-33 consists of Advanced Flexible Reusable Surface Insulation (AFRSI) blankets directly bonded to a graphite/epoxy honeycomb sandwich aeroshell. The AFRSI blankets consist of fibrous insulation enclosed in a quartz cloth. The AFRSI blankets are applied to the vehicle in large segments to minimize the number of joints between blankets. The outer surface of the blankets are coated with gray $\mathrm{C} 9$ ceramic coating which protects the blankets and provides a uniform surface emissivity of approximately 0.86 .

\section{Test Article Description}

Two test articles representative of the TPS at two locations shown in figure 13 on the leeward surface of the vehicle were tested in the 8-Foot High Temperature Tunnel. Test article 1 represented a simple butt joint between two blankets where the joint is oriented transverse to the flow direction. Test article 2 represented a $\mathrm{T}$-joint between three panels where one joint is transverse with the flow direction and the other joint is parallel with the flow direction as shown in figure 13. Both test articles were approximately $107 \mathrm{~cm}$ by $149 \mathrm{~cm}$ wide and were sized to fit into the opening in the panel holder described previously.

The test articles consisted of a $2.54 \mathrm{~cm}$ thick graphite/epoxy honeycomb sandwich panel with the AFRSI blankets bonded directly to the panel surface using RTV 560 adhesive. The honeycomb sandwich panel consisted of inner and outer skins composed of 2 plys of graphite/epoxy fabric with the core thickness reduced 
to zero around the edges of the panel. Additional plys of graphite/epoxy fabric were used to strengthen the pancl edges. The honeycomb core was made from $0.0038 \mathrm{~cm}$ thick perforated aluminum foil formed into 0.48 $\mathrm{cm}$ hexagonal cells.

Test article I represented a simple butt joint between the blanket insulation where the aeroshell is continuous and there is no need for a seal to prevent flow into the vehicle cavity. Approximately one-half of the joint length consisted of the two blankets simply butted together whereas the other half of the joint had the outer surface of the quartz cloth enclosing the blankets stitched together along the joint length.

Test article 2 represented a joint between three separate insulation blankets and included a mechanical joint in the aeroshell sandwich panels as well as the blanket insulation. The mechanical joint included a seal plate as shown in figure 14. The seal plate and the closeouts on the blankets had spring seals that pressed against each other as shown. The spring seals were composed of an Inconel wire spring tube overbraided with Nextel 312 fabric and stuffed with $0.05-0.08 \mathrm{~g} / \mathrm{cm}^{3}$ Qfelt. The seal plate was composed of a metal plate covered with blanket insulation and was attached to the aeroshell sandwich panel with mechanical fasteners, which compressed the seals between the seal plate, and the blanket closeouts. Note that the metal seal plate and a T-stiffener (see figure 14) formed a double lap joint to connect the two aeroshell sandwich panels.

\section{Test Setup}

Both TPS test articles were mounted in the wind tunnel panel holder by attaching the aeroshell sandwich panel assembly to a welded steel C-channel picture frame support which was in turn bolted to the inside walls of the cavity in the panel holder. The attachment to the panel holder was adjusted so that the surface of the blanket insulation was flush with the glass rock surface of the panel holder. For test article 2 , the mechanical joint was supported by attaching the $\mathrm{T}$-stiffener to a $\mathrm{L}$ shaped support, which was welded to the picture frame support as shown in figure 14.

\section{Instrumentation}

Test article 1 and the panel holder were instrumented with 2 microphones, one accelerometer, 4 surface pressure gages, one cavity pressure gage, 2 three-element rosette strain gages and 12 thermocouples. Test article 2 and the panel holder were instrumented with 2 microphones, 3 accelerometers, 4 surface pressure gages, 1 cavity pressure gage, 3 three-element rosette strain gages and 35 thermocouples. Video cameras were used throughout the tests and a thermograph system was used to record temperature variations over the surface of the TPS while in the flow stream. The instrumentation leads were routed through the panel holder sting. One microphone was flush mounted in the surface of the panel holder behind the TPS test article and to the

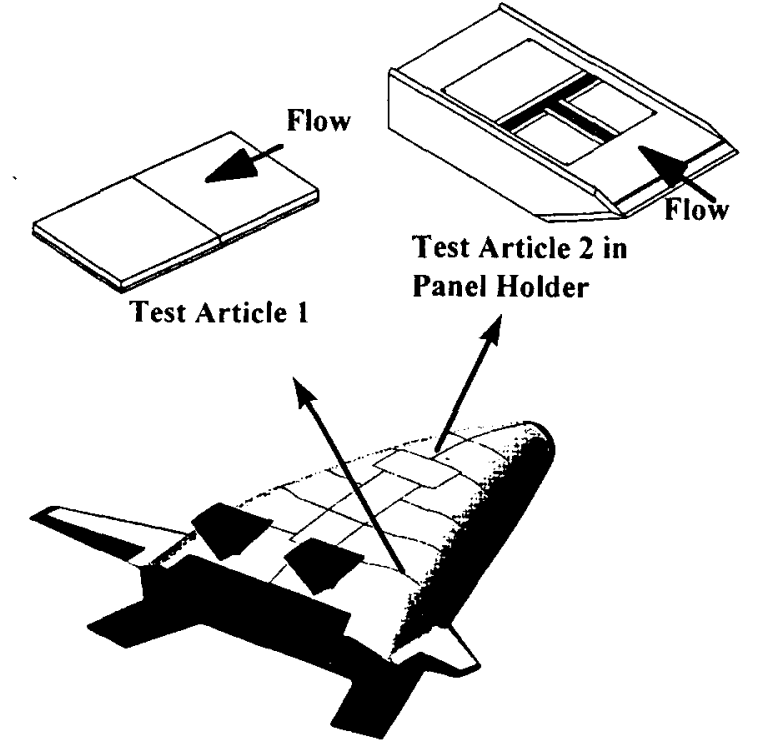

FIGURE 13. Vehicle locations for test panels.

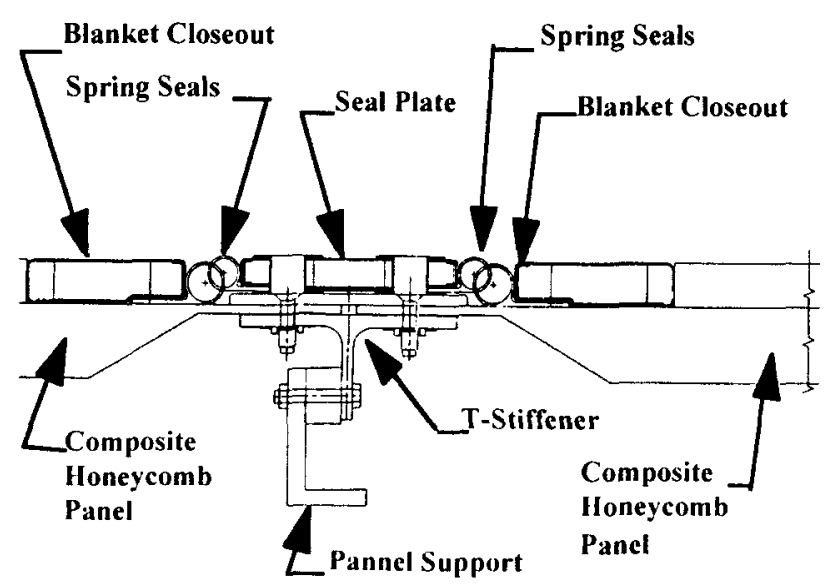

FIGURE 14. Cross-section view of transverse joint in test article number 2. 
right of center of the panel holder as shown in the layout in figure 15. The other microphone was mounted in the panel holder cavity behind the aeroshell sandwich panel. The accelerometers were mounted on the inner surface of the acroshell sandwich panels and in the center of each of the TPS blankets. The surface static pressure gages were flush with the surface of the glass rock on the panel holder and were located upstream and downstream of the test article as shown in figure 15. The cavity pressure gage was located in the panel holder cavity behind the TPS test article.

\section{Aerothermal Test Facility}

The TPS panel arrays were tested in the Langley 8-Foot High Temperature Tunnel which is a large blowdown tunnel that simulates combinations of aerodynamic heating and pressure loading representative of flight at Mach 7 and altitudes between $25 \mathrm{~km}$ and $40 \mathrm{~km}$ (Deveikis, 1974). The high energy required for the simulation is obtained by burning a mixture of methane and air under pressure in the combustor and expanding the products of combustion through the test chamber. A TPS panel array mounted in the panel holder was retained in the pod area of the tunnel (see figure 16) for protection during tunnel startup and shutdown. The panel holder is rectangular with a half-wedge leading edge and a large cavity to accommodate test panels, support structure and instrumentation. The panel holder was covered with a one-inch thick layer of glassrock to protect the steel structure from the aerodynamic heating of the tunnel. Boundary-layer trips and side fences assured uniform turbulent flow over the panel surface. Pressure in the cavity behind the test panel was vented to the base of the panel holder to produce a differential pressure loading during aerothermal tests. Banks of radiant lamps, located in the pod, were used to preheat the TPS panel array through a prescribed portion of an entry thermal profile prior to rapid insertion into the Mach 7 stream.

\section{Test Procedure}

The test procedure consisted of preheating the TPS panel array in the pod below the test chamber, starting the wind tunnel, retracting the heater banks, inserting the panel holder/TPS array into the flow, conducting aerothermal heating tests, retracting the panel holder assembly, covering the TPS panel array with the heaters, stopping the tunnel flow, and allowing uncontrolled cooling of the TPS panel array. A diagram showing the test sequence for a typical tunnel run is shown in figure 17. The tunnel flow conditions and the panel holder angle of attack can be set before the model is inserted into the flow or can be adjusted during the test as desired. Data were recorded throughout the test including the preheat and the model cooling. Static measurements (temperature, static strains, pressure, heat flux, and mass flow) were recorded at the rate of 10 times per second during the preheat and cooling portion of the test and 50 times per second during the tunnel startup, model insertion, flow tests, model retraction, and tunnel shutdown. Dynamic measurements (strain, acceleration, sound) were recorded at the rate of 5000 times per second during insertion and withdrawal of the test article from the flow and while the test article was in the tunnel flow. Select data channels were displayed in graphical form during the tests so that the performance of the TPS panel array could be evaluated, and if necessary, the test aborted to prevent damage to the test article.

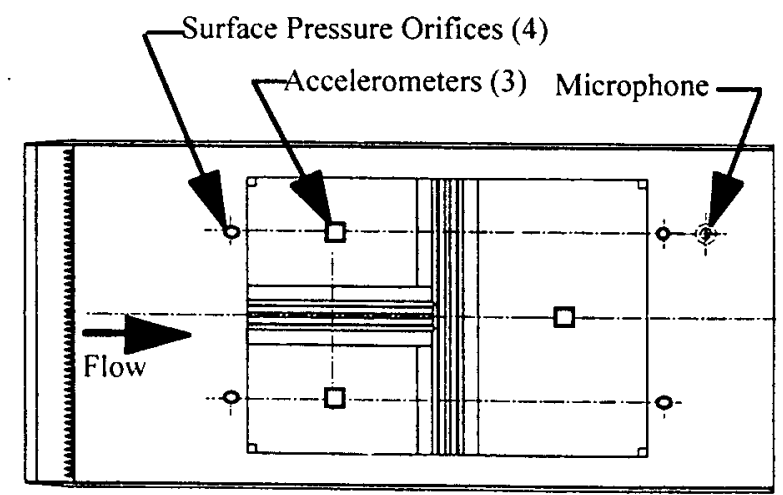

FIGURE 15. Layout for model 2 TPS blanked array in panel holder.

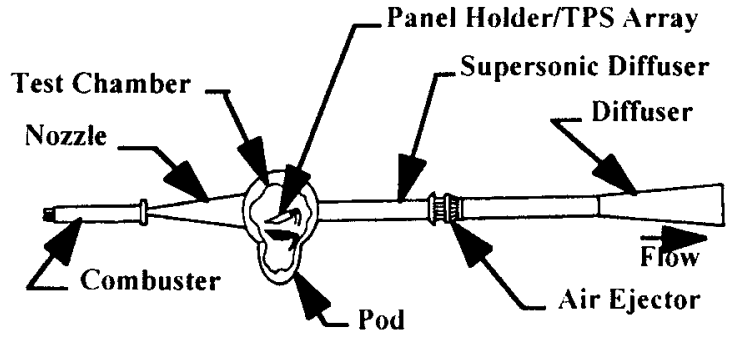

FIGURE 16 Diagram of 8-Foot High Temperature Tunnel. 


\section{RESULTS AND DISCUSSION}

This section describes the preliminary interpretation of results for both the windward and leeward surface TPS panels. A more comprehensive evaluation of the measured data is in progress and a detailed report is planned.

\section{Windward Surface TPS}

A total of 16 aerothermal tests and 7 radiant heater tests up to temperatures of $1273 \mathrm{~K}$ or greater were conducted on the windward surface TPS. The test conditions for the TPS panel array were representative of the aerothermal conditions expected during the X-33 flights. Figure 18 shows surface pressure versus surface temperature variations for typical X-33 flights at locations on the vehicle for which the TPS test panel was designed. Also shown on the figure are the 8-Foot High Temperature Tunnel test envelope.

The tests conducted on the windward surface TPS panel array are summarized in Table I. The first three tests listed and test number 13 were thermal tests that were used to check out the radiant heater system and to measure the thermal response of the TPS panel array. The other thermal tests (test numbers 5,6 , and 8 ) were intended to be aerothermal tests but were aborted before insertion into the tunnel flow due to problems with the tunnel startup. For the thermal cycles and all the preheat cycles, the surface of the TPS panel array was heated to the maximum preheat temperature at a rate of $6 \mathrm{~K} / \mathrm{sec}$ and held constant until insertion into the tunnel stream or until completion of the thermal cycle. All the tests except number 21 were at surface temperatures and pressures below the design limit. Test number 21 was conducted to determine the overdesign capabilities of the TPS array by exceeding the design limit for the surface temperature and pressure differential across the thickness of the panel.

The first aerothermal test, number 4 , had the most benign test conditions possible for the test setup. The maximum preheat temperature was $778 \mathrm{~K}$, the tunnel combustor pressure was $6.9 \mathrm{MPa}$ and the angle-of-attack was $5^{\circ}$. The preheat temperature and the angle-of-attack for the first aerothermal tests were selected to introduce only small temperature gradients into the TPS panel array and to keep the pressure differential across the thickness of the TPS panel (i.e., between exposed surface of TPS panel and the plenum) to a minimum. The next 2 aerothermal tests (test numbers 7 and 9) expanded the flow and thermal conditions to induce a larger temperature gradient and pressure differential across the thickness of the TPS panel array until the TPS panel design conditions were reached. Test numbers 10 and 11 were repeats of test number 9 . Test number 12 was conducted with TPS panel design conditions (i.e., test number 9) but with the surface of the leading edge of the center panel recessed by $0.15 \mathrm{~cm}$. below the surface of the upstream panel, creating a step between the overlapping seals and the downstream panel..

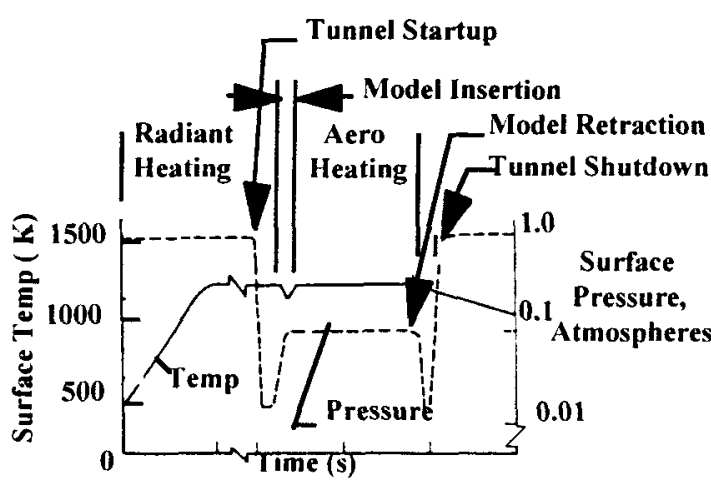

FIGURE 17. Test sequence for typical aerothermal test cycle.

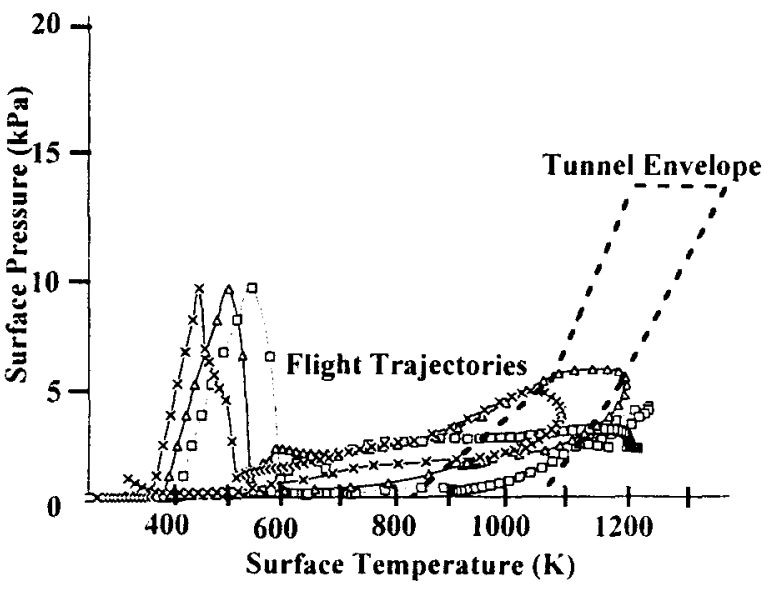

FIGURE 18. Typical X-33 flight conditions and 8-Foot High Temperature Tunnel Conditions

Unfortunately, a tunnel anomaly occurred during test number 12 that resulted in complete destruction of the TPS test panel array. A new TPS panel array was fabricated and installed in the panel holder and the test 
resumed. Test number 13 was a thermal cycle test of the new TPS panel array. Test number 14 was a repeat of test number 11 at the X-33 design conditions to verify the performance of the new TPS panel array. Tests number 15-17, and 19-2.3 were conducted to determine how various off-design conditions would effect the performance of the TPS panel array. Tests number 15 and 16 were conducted with the surface of the leading edge of the center panel recessed below (test number 15) or protruding above (test number 16) the surface of the upstream panel by $0.23 \mathrm{~cm}$. For test number 17 , the trailing edge center flap of panel number 1 was removed as shown in figure 19 to simulate possible damage during flight. Test number 18 was a repeat of the $\mathrm{X}-33$ design conditions but with a new panel number 1 with the trailing edge center flap in place and with the number 6 panel side seals modified to be more representative of an interface seals between the metallic TPS and a carbon-carbon fairing planned for the X-33. For test numbers 19 and 23, a portion of the primary seal on panel number 3 was removed as shown in figure 19. The portion of the primary seal removed for test number 19 was replaced for test numbers 20 through 22 . For test numbers 20 and 22 , the downstream and upstream fasteners respectively for panel number 4 were removed for the test. For test number 21 , the panel holder angle-of-attack was increased to $12^{\circ}$ which results in a surface temperature and pressure differential across the thickness of the panel slightly larger than the X-33 design conditions.

Throughout the tests, the outer honeycomb sandwich panel maintained a uniform appearance, with no obvious signs of warping, wrinkling, or deterioration. The appearance of all attachment hardware, supports, insulation encapsulation, and underlying structure indicated no evidence of obvious degradation or even discoloration. However, some wrinkling (thermal buckling) of the outer overlapping seals occurred during each test and produced some variations in the heating to the surface of the panels. The overlapping side seals between the TPS test article and the panel holder fluttered at flow conditions representative of the X-33 flight conditions (test number 9), thus destroying the overlapping seals along most of the length of the side edges of the test article. However, the underlying rope side seals, reinforced with ceramic cement, performed well enough for testing to continue. Since the overlapping seals between the TPS panels are similar to the side seals but did not flutter, it appears that the alignment of the flow parallel with the side seals was the critical difference that resulted in the flutter of the side seals. For tests number 13 with the new test article, the length of the overlapping side seals was reduced from $2.5 \mathrm{~cm}$ to $1.9 \mathrm{~cm}$ to reduce the potential for the side seals to flutter. However, the side seals fluttered and were destroyed during run number 13. Although the overlapping seals between the TPS panels did not show any evidence of flutter, care must be exercised in designing the TPS for the X-33 to consider flutter for any of the overlapping seals that may be closely aligned with the local flow direction.

One of the primary objectives of the test was to verify that the panel-to-panel seals could prevent damaging subsurface hot gas flow. A preliminary static test, which consisted of hooking a vacuum pump to the outlet tube from the flow meter, indicated that a relatively large flow could be generated through the seals with negligible pressure drop across the seals. However, during the hot gas flow tests, sustained pressure differences of up to $5.2 \mathrm{kPa}$ were measured across the seals without any evidence of damaging hot gas flow. Even with intentional vertical offsets of the adjacent panels, removal of a fastener, and removal of up to 20 $\mathrm{cm}$ of the outer panel-to-panel seal, there were no evidence of damaging subsurface hot gas flows. Measurements from the flow meter, thermocouples, and heat flux gages are being studied to better understand this behavior and to generate quantitative seal leak rates.

Typical aerothermal test results for the TPS panel array during test number 11 at X-33 design conditions are shown in figures 20 and 21 . Temperatures on the outer and inner honeycomb sandwich face sheets and on the back side of the insulation pan for the center panel are shown in figure 20 . The heat flux measured under the seals between panels 3 and 4 is shown in figure 21 . The temperatures and heat flux are shown as a function of time for both the radiant preheat and the aerothermal portions of the test. 


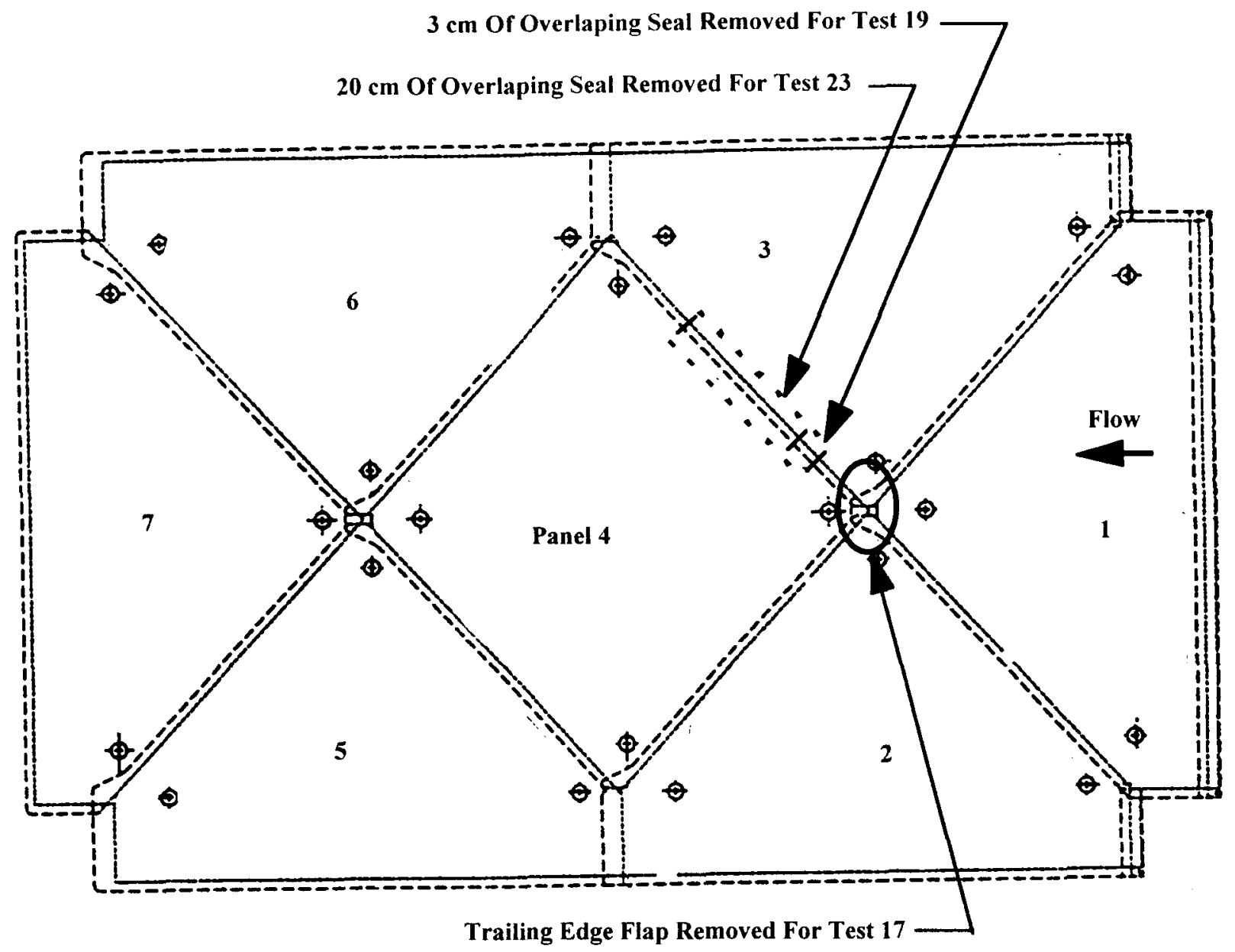

FIGURE 19 Simulated seal damage to TPS panel array.

The temperature distributions shown in figure 20 indicate that the TPS panel array performed as expected thermally. The outer face sheet temperature measurement was erratic during the preheat phase just before insertion into the air flow due to startup of the wind tunnel. Also the outer face sheet temperature dropped approximately $200^{\circ} \mathrm{C}$ during the time the radiant heaters were cut off and the model was inserted into the air stream. This drop in surface temperature caused a negative (surface face sheet cooler than the inside face sheet) thermal gradient on the panel which quickly reversed as the model was inserted into the air stream. After insertion of the panel into the flow the surface temperature increased above the radiant preheat temperature and approached an equilibrium value near the end of the 60 second tunnel run. The temperatures on the inside face sheet and on the back side of the insulation package were only slightly affected by the tunnel startup and insertion into the flow. After withdrawal of the model from the flow, a negative thermal gradient again occurred as the outer face sheet cooled faster than the inner face sheet. The temperature on the back side of the insulation package continued to rise and reached a maximum well after the aerothermal test was completed.

The measured heat flux values beneath the panel-to-panel seal (figure 21) also displayed some variations during tunnel startup and insertion of the model into the flow. The heat flux increased while the TPS array was in the tunnel flow similar to increases noted in figure 20 for the temperature of the outer face sheet. During the radiant preheat the measured heat flux was primarily due to radiation from the surfaces of the primary and secondary seals. During tunnel startup and insertion of the model into the tunnel, some of the measured heat flux could be due to hot air impinging on the sensor. However, the lack of large erratic increases in the heat flux and the good correlation of the heat flux with the surface temperature suggests that there was little or no hot gas impinging on the heat flux sensor during either the tunnel startup or the tunnel run. 